\title{
Acetazolamide attenuates chemical-stimulated but not thermal-stimulated acute pain in mice
}

\author{
Ya-jie SUN , Ying CHEN, Chong PANG, Ning WU*, Jin LI* \\ Department of New Drug Evaluation, Beijing Institute of Pharmacology and Toxicology, Beijing 100850, China
}

\begin{abstract}
Aim: Acetazolamide (AZA), a carbonic anhydrase (CA) inhibitor, has been found to alleviate inflammatory and neuropathic pain in rats. In the present study, we investigated the effects of AZA on thermal- and chemical-stimulated acute pain in mice and the possible mechanisms underlying the effects.

Methods: Five acute pain models based on thermal and chemical stimuli were established to investigate the effects of AZA on different types of nociception in mice. The antinociceptive effects of methazolamide (another CA inhibitor) and diazepam (a positive allosteric modulator of $\mathrm{GABA}_{\mathrm{A}}$ receptor) were also examined. The drugs were administered either intraperitoneally (ip) or intrathecally.

Results: AZA (50-200 mg/kg, ip) did not produce analgesia in two thermal-stimulated acute pain models, ie, mouse tail-flick and hotplate tests. In contrast, AZA (50-200 mg/kg, ip) dose-dependently reduced paw licking time in both capsaicin and formalin tests in mice. A similar result was observed in a mouse acetic acid-induced writhing test. However, AZA (10 nmol/mouse, intrathecally) did not produce significant analgesia in the 3 chemical-stimulated acute pain models. In addition, methazolamide (50-200 mg/kg, ip) and diazepam $(0.25-1.0 \mathrm{mg} / \mathrm{kg}$, ip) did not produce significant analgesia in either thermal- or chemical-stimulated acute pain.

Conclusion: AZA produces analgesia in chemical-stimulated, but not thermal-stimulated acute pain in mice. The attenuation of

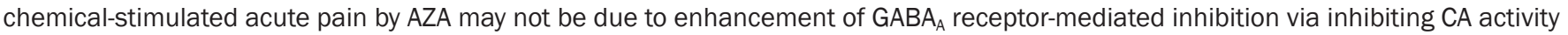
but rather a peripheral ion channel-related mechanism.
\end{abstract}

Keywords: acetazolamide; methazolamide; diazepam; analgesia; tail-flick test; hot-plate test; capsaicin test; formalin test; acetic acidinduced writhing test; carbonic anhydrase; $\mathrm{GABA}_{\mathrm{A}}$ receptor

Acta Pharmacologica Sinica (2014) 35: 41-47; doi: 10.1038/aps.2013.149; published online 16 Dec 2013

\section{Introduction}

Pain is defined as an unpleasant sensory and emotional experience associated with actual or potential tissue damage or described in terms of such damage $\mathrm{e}^{[1]}$. This condition is classified as acute pain or chronic pain. Acute pain serves as a warning of disease or a threat to the body, including physical (thermal and mechanical stimuli) and chemical (capsaicin, formalin and acetic acid stimuli)-induced pain. Chronic pain is a type of disease and is often classified as chronic inflammatory pain or neuropathic pain.

Acetazolamide (AZA), a sulfonamide derivative, has various pharmacological activities. It is well known that AZA is a carbonic anhydrase (CA) inhibitor that has been shown to be effective in the treatment of glaucoma through the inhibi-

\footnotetext{
$\S$ Now at Beijing Institute of Microbiology and Epidemiology, Beijing 100071, China.

* To whom correspondence should be addressed.

E-mail jinli9802@163.com (Jin LI); wuning7671@126.com (Ning WU)

Received 2013-05-05 Accepted 2013-09-18
}

tion of $\mathrm{HCO}_{3}{ }^{-}$production ${ }^{[2]}$. AZA is a diuretic agent that can increase renal potassium excretion ${ }^{[3]}$ and alkalinize urine ${ }^{[4]}$ and it is a potent vasodilator of the cerebral vasculature as well ${ }^{[5]}$. Most recently, increasing interest has been focused on AZA as a prophylactic and therapeutic agent for acute mountain sickness $^{[6]}$.

AZA has also been reported to relieve inflammation- and peripheral nerve injury-induced chronic pain. Injection with $3 \%$ carrageenan suspension into the left gastrocnemius muscle belly induced typical inflammatory pain in rats, resulting in thermal hyperalgesia and mechanical allodynia. However, $24 \mathrm{~h}$ after carrageenan injection in rats, intraperitoneal (ip) or intrathecal administration of AZA attenuated the inflammation-induced thermal hyperalgesia ${ }^{[7]}$. In a rat spinal nerve ligation (SNL) model, a typical neuropathic pain model, intrathecal administration of AZA not only reduced mechanical allodynia but also produced synergistic analgesia along with midazolam ${ }^{[8]}$. In inflammatory and neuropathic pain, a depolarizing efflux of $\mathrm{HCO}_{3}{ }^{-}$via $\mathrm{GABA}_{\mathrm{A}}$ instead of the normally occurring influx of $\mathrm{Cl}^{-}$can reduce the efficacy of $\mathrm{GABA}_{\mathrm{A}}$ 
receptor-mediated hyperpolarizing inhibition. AZA decreases the production of $\mathrm{HCO}_{3}^{-}$by inhibiting $\mathrm{CA}$, which further enhances the efficacy of $\mathrm{GABA}_{\mathrm{A}}$ receptor-mediated inhibition, eventually alleviating inflammatory and neuropathic pain ${ }^{[7,8]}$.

Thermal and chemical stimuli are the two main pathways that induce acute pain and have different neurobiological mechanisms. First, thermal-stimulated pain is transmitted by $A \delta$ and $C$ fibers, whereas chemical-stimulated pain is only transmitted by $C$ fibers ${ }^{[9]}$. Second, the role of ion channels and receptors in thermal-stimulated acute pain is not completely the same as in chemical-stimulated acute pain ${ }^{[10]}$. However, whether AZA produces analgesia in acute pain remains unknown.

In the current study, using five models of acute pain based on thermal or chemical stimuli, we tried to answer the following questions: (1) does AZA have an analgesic effect on the two types of acute pain induced by thermal and chemical stimuli? and (2) does AZA attenuate acute pain by enhancing the efficacy of $\mathrm{GABA}_{\mathrm{A}}$ receptor-mediated inhibition via a similar mechanism as that of AZA's attenuation of inflammatory and neuropathic pain? To better understand the possible mechanism, the effects of methazolamide (MZA), another CA inhibitor, and diazepam, a positive allosteric modulator that activates $\mathrm{GABA}_{\mathrm{A}}$ receptors ${ }^{[11]}$, were investigated in acute pain and compared with the effects of AZA.

\section{Materials and methods}

\section{Animals and drugs}

Male and female KunMing mice weighing 18-22 g were obtained from Beijing Animal Center and housed at a temperature of $21 \pm 1^{\circ} \mathrm{C}$ under a $12 \mathrm{~h}$ light/12 h dark cycle (lights on at 7:00 AM, lights off at 7:00 PM) and with food and water ad libitum. All animal experiments were conducted following the related regulations of the Institutional Review Committee for the Use of Animals.

AZA (Sigma, St Louis, MO, USA) and MZA (Sigma, St Louis, MO, USA) were separately dissolved in $1 \mathrm{~mol} / \mathrm{L} \mathrm{NaOH}$, and the $\mathrm{pH}$ was adjusted to 7.4 with $1 \mathrm{~mol} / \mathrm{L} \mathrm{HCl}$. The solutions were then diluted with isotonic $(0.9 \% \mathrm{NaCl})$ saline to achieve 50, 100, and $200 \mathrm{mg} / \mathrm{kg}$ solutions for ip administration and a $10 \mathrm{nmol}$ solution for intrathecal administration. Isotonic $(0.9 \% \mathrm{NaCl})$ saline solution was used as a control.

Diazepam was administered intraperitoneally at $0.25,0.5$, or $1 \mathrm{mg} / \mathrm{kg}$.

\section{Tail-flick test}

Male mice were used in this test. The method is an adaptation of that described by Delporte et $a l^{[12]}$. Lower and higher light intensities of 8 and 12, respectively, were used. A cut-off time of $16 \mathrm{~s}$ was chosen to avoid tissue damage. The tail-flick test was performed four times (at 30, 60, 90 and $120 \mathrm{~min}$ ) postdrug administration. AZA (50, 100, or $200 \mathrm{mg} / \mathrm{kg}$, ip), MZA $(50,100$, or $200 \mathrm{mg} / \mathrm{kg}$, ip), diazepam $(0.25,0.5$, or $1 \mathrm{mg} / \mathrm{kg}$, ip) or saline $(10 \mathrm{~mL} / \mathrm{kg}$, ip) was administered. The results were expressed as the possible maximum analgesia percentage (PMAP) (\%), which was calculated according to the formula
$\left[\left(T_{1}-T_{0}\right) /\left(T_{2}-T_{0}\right)\right] \times 100$, where $T_{0}$ is the baseline latency, $T_{1}$ is the latency obtained after drug administration, and $T_{2}$ is the cutoff time.

\section{Hot-plate test}

Female mice were used in this test. The procedure followed the protocol described by Jones et $a l^{[13]}$. Two different hotplate temperatures, $52^{\circ} \mathrm{C}$ and $55^{\circ} \mathrm{C}$, were used. A cut-off time of $60 \mathrm{~s}$ was chosen to avoid tissue damage. The hot-plate test was performed four times (at 30, 60, 90, and $120 \mathrm{~min}$ ) postdrug administration. AZA (50, 100, or $200 \mathrm{mg} / \mathrm{kg}$, ip), MZA (50, 100, or $200 \mathrm{mg} / \mathrm{kg}$, ip), diazepam $(0.25,0.5$, or $1 \mathrm{mg} / \mathrm{kg}$, ip) or saline $(10 \mathrm{~mL} / \mathrm{kg}$, ip) was administered. The results were expressed as PMAPs.

\section{Capsaicin test}

Male mice were used in this test. The method followed the procedure of Snatol et $a l^{[14]}$, with certain modifications. The mice were given saline $(10 \mathrm{~mL} / \mathrm{kg}$, ip), AZA $(50,100$, or 200 $\mathrm{mg} / \mathrm{kg}$, ip), MZA (50, 100, or $200 \mathrm{mg} / \mathrm{kg}$, ip) or diazepam $(0.25,0.5$, or $1 \mathrm{mg} / \mathrm{kg}$, ip) $30 \mathrm{~min}$ before the right hind paw was injected with $10 \mu \mathrm{L}$ capsaicin $(3 \mu \mathrm{g} /$ paw) prepared in $10 \%$ Tween-80 and $10 \%$ ethanol. Nociception was evaluated immediately after injection of capsaicin and quantified based on paw-licking time during a 5-min period. In addition, AZA (10 nmol/mouse, $5 \mu \mathrm{L}$ ) was administered by the intrathecal route. The method of intrathecal injection followed the procedure of Hylden et $a l^{[15]}$. In brief, the mice were administered AZA by intrathecal injection with a $50-\mu \mathrm{L}$ microsyringe between lumbar segments 5 and 6 , with the sudden appearance of sideways movements by the mice's tails as a sign of success. Ten minutes after AZA intrathecal administration, the mice received a capsaicin injection.

\section{Formalin test}

Male mice were used in this test. The formalin test was conducted as previously described by Couto et al ${ }^{[16]}$. The male mice were given saline $(10 \mathrm{~mL} / \mathrm{kg}$, ip), AZA $(50,100$, or 200 $\mathrm{mg} / \mathrm{kg}$, ip), MZA (50, 100, or $200 \mathrm{mg} / \mathrm{kg}$, ip) or diazepam $(0.25,0.5$, or $1 \mathrm{mg} / \mathrm{kg}$, ip) $30 \mathrm{~min}$ before the right hind paw was injected with $20 \mu \mathrm{L} 2 \%$ formalin solution. Nociception was evaluated immediately after the injection of formalin and quantified based on the total paw licking time in the early phase (phase 1: 0-5 min) and the late phase (phase 2: 15-30 min). In addition, AZA (10 nmol/mouse, $5 \mu \mathrm{L})$ was administered by the intrathecal route. Ten minutes after AZA intrathecal administration, the mice received a formalin injection.

\section{Acetic acid-induced writhing test}

Male mice were used in this test. This procedure was described by Chiba et al ${ }^{[17]}$. The male mice were given saline (10 mL/kg, ip), AZA (50, 100, or $200 \mathrm{mg} / \mathrm{kg}$, ip), MZA (50, 100 , or $200 \mathrm{mg} / \mathrm{kg}$, ip) or diazepam $(0.25,0.5$, or $1 \mathrm{mg} / \mathrm{kg}$, ip) $30 \mathrm{~min}$ before the injection of acetic acid $(0.6 \%, 20 \mathrm{~mL} / \mathrm{kg}$, ip). The number of writhing movements was counted for $15 \mathrm{~min}$ beginning $5 \mathrm{~min}$ after the injection of acetic acid. In addition, 
AZA $(10 \mathrm{nmol} /$ mouse, $5 \mu \mathrm{L})$ was administered by the intrathecal route. Ten minutes after AZA intrathecal administration, the mice received a acetic acid injection.

\section{Locomotor activity test}

Before the analgesic properties of the drugs were tested, their effects on locomotor activities were evaluated. Mice were placed in individual locomotor activity cages without drug treatment for $30 \mathrm{~min}$, and the locomotor activities of each mouse were recorded. The mice were grouped according to their basal locomotor activities. The mice were then injected with saline $(10 \mathrm{~mL} / \mathrm{kg}$, ip) or AZA (200 or $400 \mathrm{mg} / \mathrm{kg}$, ip), MZA (200 or $400 \mathrm{mg} / \mathrm{kg}$, ip) or diazepam (1 or $2 \mathrm{mg} / \mathrm{kg}$, ip) $30 \mathrm{~min}$ before they were placed in individual locomotor activity cages and assessed for $1 \mathrm{~h}$. For intrathecal administration of AZA (10 and $30 \mathrm{nmol} / \mathrm{mouse}$ ), locomotor activities were recorded beginning at $10 \mathrm{~min}$ after the intrathecal injection.

\section{Statistical analysis}

The data were expressed as the mean \pm SEM and analyzed with SPSS software (version 18.0). The data from the capsaicin, formalin and acetic acid-induced writhing tests (drugs with ip administration) and locomotor activity test were analyzed by one-way ANOVA, followed by Dunnett's $t$-test. The data from the tail-flick and hot-plate tests were analyzed by twoway ANOVA with repeated measurement, followed by Tukey's test. The data from the intrathecal administration of AZA were analyzed using a Student's $t$-test. $P<0.05$ was considered statistically significant.

\section{Results}

AZA failed to produce analgesia in thermal-stimulated acute pain but attenuated chemical-stimulated acute pain

In the tail-flick test, AZA (50, 100, or $200 \mathrm{mg} / \mathrm{kg}$, ip) failed to increase the latency of tail flicking from 0 to 120 min after treatment under lower and higher intensities, and the PMAPs were less than $10 \%$ (lower intensity, treatment: $F_{3,36}=0.3546$, $P>0.05$; time: $F_{3,36}=3.142, P<0.05$; treatment $X$ time: $F_{3,36}=0.1674$, $P>0.05$; higher intensity, treatment: $F_{3,35}=0.7601, P>0.05$; time: $F_{3,35}=4.142, P<0.05$; treatment $X$ time: $F_{3,35}=1.157, P>0.05$ ) (Figure $1 \mathrm{~A}$ ). The same result was obtained in the hot-plate test at $52^{\circ} \mathrm{C}$ and $55{ }^{\circ} \mathrm{C}$ hot-plate temperatures $\left(52^{\circ} \mathrm{C}\right.$ hot-plate, treatment: $F_{3,36}=0.3689, P>0.05$; time: $F_{3,36}=3.000, P<0.05$; treatment $X$ time: $F_{3,36}=0.3344, P>0.05 ; 55^{\circ} \mathrm{C}$ hot-plate, treatment:
A

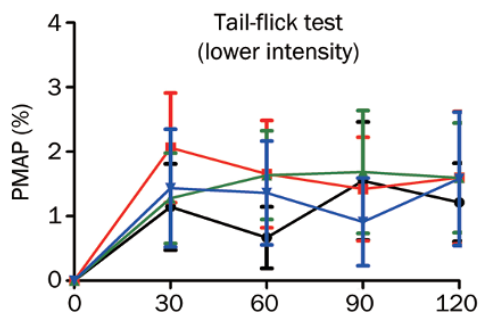

B

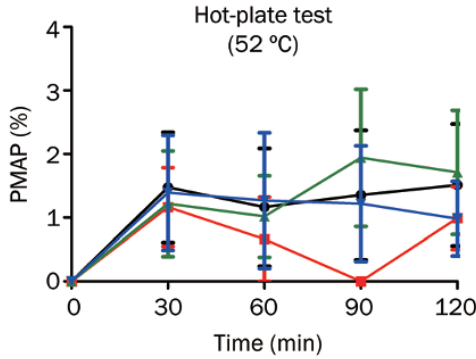

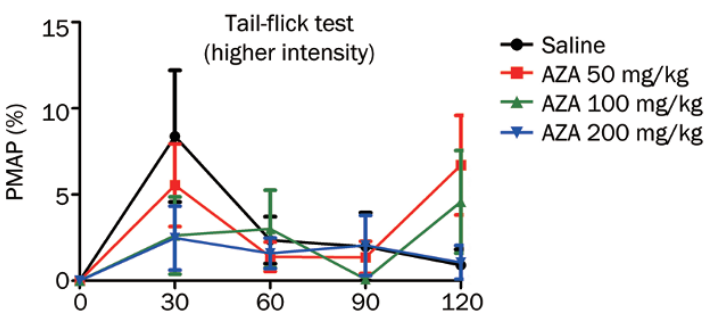

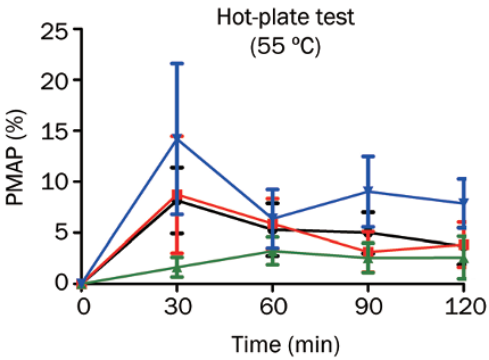

Formalin test

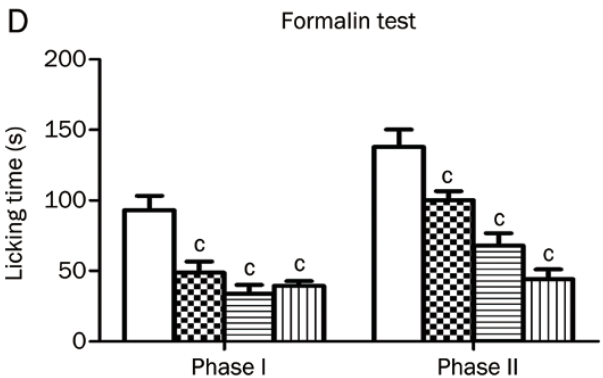

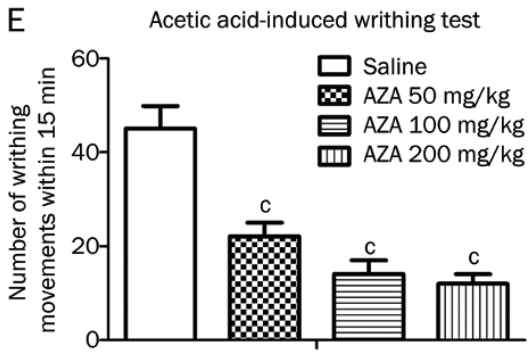

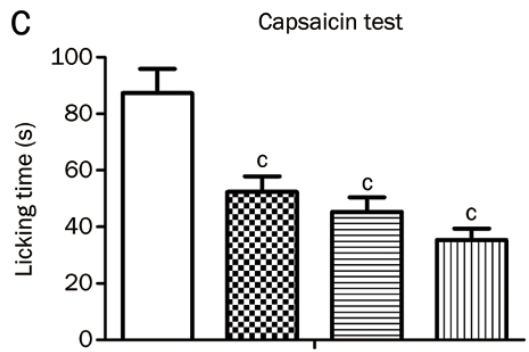

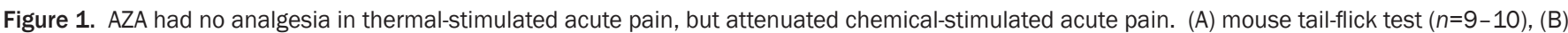

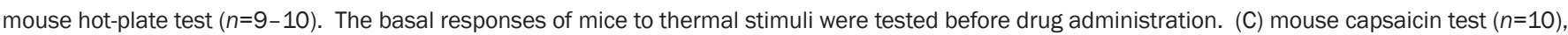

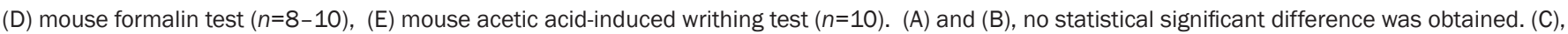
(D), and (E), ${ }^{\mathrm{C}} \mathrm{P}<0.01$ vs control. 
$F_{3,34}=1.811, P>0.05$; time: $F_{3,34}=5.421, P<0.05$; treatment $X$ time: $\left.F_{3,34}=0.6671, P>0.05\right)$ (Figure $1 \mathrm{~B}$ ). These results suggested that AZA produced no analgesia in thermal-stimulated acute pain. In the capsaicin test, compared with vehicle treatment, administration of AZA at a dose of 50,100, or $200 \mathrm{mg} / \mathrm{kg}$ significantly reduced paw licking time $\left(F_{3,36}=13.849, P<0.001\right)$ (Figure $1 C)$. In the formalin test, similar to what was observed in the capsaicin test, AZA (50, 100, or $200 \mathrm{mg} / \mathrm{kg}$, ip) dose-dependently reduced paw-licking time in both the first and the second phases (first phase: $F_{3,34}=13.305, P<0.001$; second phase: $F_{3,34}=21.327, P<0.001$ ) (Figure 1D). In the acetic acid-induced writhing test, compared with vehicle treatment, AZA (50, 100, or $200 \mathrm{mg} / \mathrm{kg}$, ip) decreased the number of writhing movements in a dose-dependent manner $\left(F_{3,36}=20.750, P<0.001\right)$ (Figure 1E). In addition, AZA at a dose of $200 \mathrm{mg} / \mathrm{kg}$ (ip) did not decrease locomotor activities (Figure 2), suggesting that the analgesic effect of AZA is not caused by its sedative effect. All of these results suggested that AZA has the potential to relieve chemical-stimulated acute pain, including cutaneous pain and visceral pain.

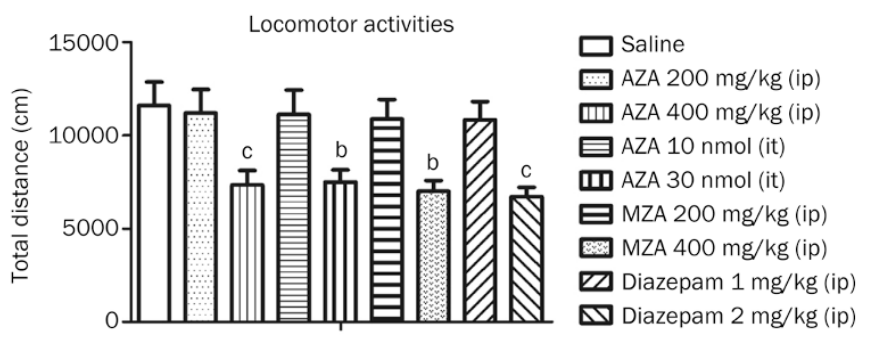

Figure 2. Effects of AZA, MZA, and diazepam on locomotor activities. $n=10$ /group. ${ }^{b} P<0.05,{ }^{\circ} P<0.01$ vs control.

To determine the possibility of a peripheral or spinal mechanism, intrathecal administration of AZA was conducted. Compared with vehicle treatment, AZA (10 nmol/mouse, intrathecal injection) did not significantly reduce nociceptive responses in the capsaicin, formalin and acetic acid-induced writhing tests (Figure 3), whereas positive-control morphine (10 nmol/mouse, intrathecal injection) significantly reduced paw licking time in both the first and the second phases (data not shown). These results suggested that AZA attenuates chemical-induced acute pain by a peripheral but not spinal mechanism.

\section{MZA failed to attenuate thermal- and chemical-stimulated acute} pain

The effects of MZA, another CA inhibitor, were compared with AZA's effects. In contrast to AZA either inhibiting CA or affecting other ion channels, MZA merely inhibits CA and has no action on other ion channels. In the tail-flick test, MZA $(50,100$, or $200 \mathrm{mg} / \mathrm{kg}$, ip) did not increase the latency of tail flicking (treatment: $F_{3,36}=0.1875, P>0.05$; time: $F_{3,36}=3.093$, $P<0.05$; treatment $X$ time: $F_{3,36}=0.4715, P>0.05$ ) (Figure $4 \mathrm{~A}$ ). The same result was observed in the hot-plate test (treatment: $F_{3,36}=0.3807, P>0.05$; time: $F_{3,36}=3.027, P<0.05$; treatment $X$ time: $F_{3,36}=0.2328, P>0.05$ ) (Figure 4B). Moreover, MZA (50, 100 , or $200 \mathrm{mg} / \mathrm{kg}$, ip) had no significant analgesic effects in the capsaicin, formalin and acetic acid-induced writhing tests (capsaicin test, $F_{3,36}=0.098, P>0.05$; formalin test, first phase: $F_{3,36}=2.956, P>0.05$, second phase: $F_{3,36}=1.335, P>0.05$; acetic acid-induced writhing test, $F_{3,36}=0.159, P>0.05$ ) (Figure $4 \mathrm{C}-4 \mathrm{E}$ ), which was not consistent with AZA's effects on chemical-stimulated acute pain. In addition, MZA at a dose of $200 \mathrm{mg} / \mathrm{kg}$ (ip) did not decrease locomotor activities (Figure 2). These results showed that MZA failed to produce analgesia in acute pain, suggesting that inhibition of CA might not play a role in AZA-related efficacy in the relief of chemical-stimulated acute pain.

Diazepam failed to attenuate thermal- and chemical-stimulated acute pain

In the tail-flick test, diazepam $(0.25,0.5$, or $1 \mathrm{mg} / \mathrm{kg}$, ip) did not increase the latency of tail flicking (lower intensity, treatment: $F_{3,36}=0.1294, P>0.05$; time: $F_{3,36}=3.710, P<0.05$; treatment $X$ time: $F_{3,36}=0.1106, P>0.05$; higher intensity, treatment: $F_{3,36}=1.526, P>0.05$; time: $F_{3,36}=5.292, P<0.05$; treatment $X$ time: $F_{3,36}=0.6898, P>0.05$ ) (Figure $5 \mathrm{~A}$ ). The same result was observed in the hot-plate test $\left(52{ }^{\circ} \mathrm{C}\right.$ hot-plate, treatment: $F_{3,36}=0.1783, P>0.05$; time: $F_{3,36}=7.213, P<0.05$; treatment $X$ time: $F_{3,36}=0.5133, P>0.05 ; 55^{\circ} \mathrm{C}$ hot-plate, treatment: $F_{3,36}=1.126$, $P>0.05$; time: $F_{3,36}=3.267, P<0.05$; treatment $X$ time: $F_{3,36}=1.479$, $P>0.05$ ) (Figure 5B). Compared with vehicle treatment, diaz-
A

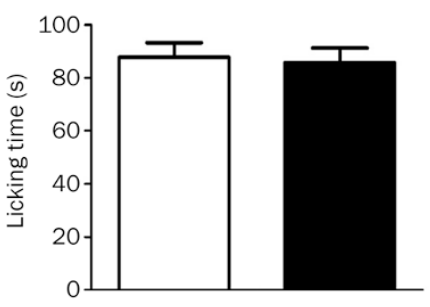

B

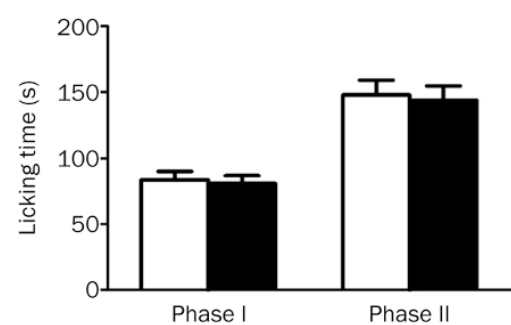

C

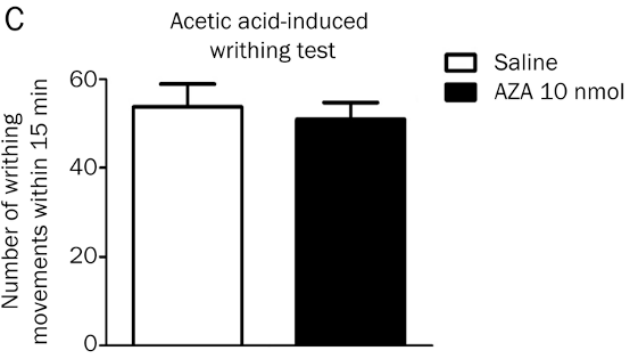

Figure 3. AZA had no analgesia in chemical-stimulated acute pain by intrathecal injection. (A) mouse capsaicin test. (B) mouse formalin test. (C) mouse acetic acid-induced writhing test. $n=10 /$ group. No statistical significant difference was obtained. 

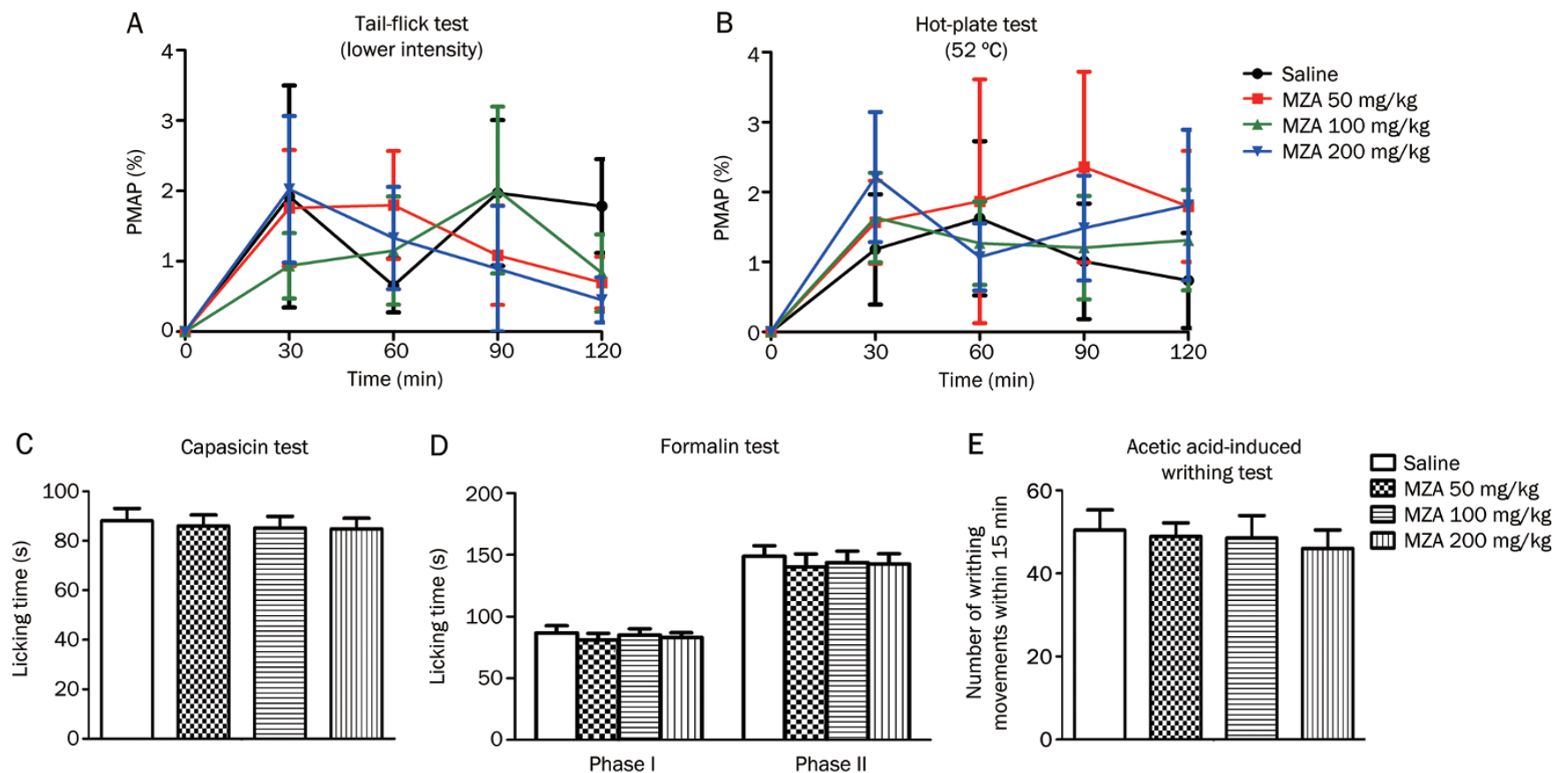

Figure 4. MZA did not produce analgesia in both thermal- and chemical-stimulated acute pain. (A) mouse tail-flick test, (B) mouse hot-plate test. The basal responses of mice to thermal stimuli were tested before drug administration. (C) mouse capsaicin test, (D) mouse formalin test, (E) mouse acetic acid-induced writhing test. $n=10 /$ group. No statistical significant difference was obtained.

A

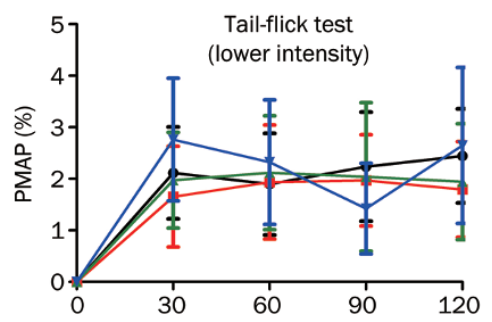

B

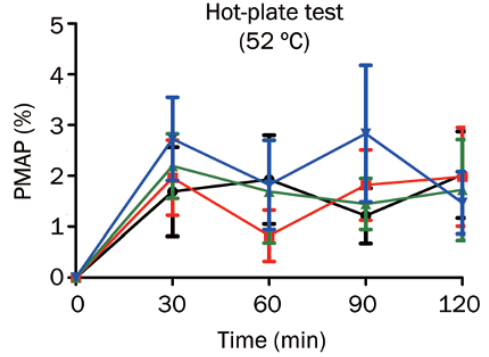

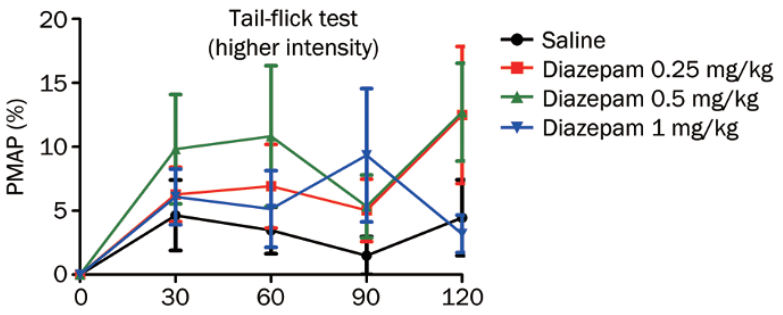

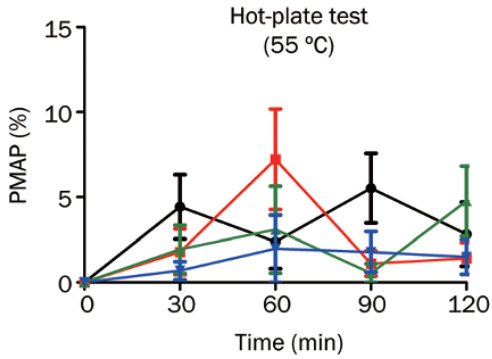

C

Capsaicin test

D

Formalin test

E

Acetic acid-induced writhing test
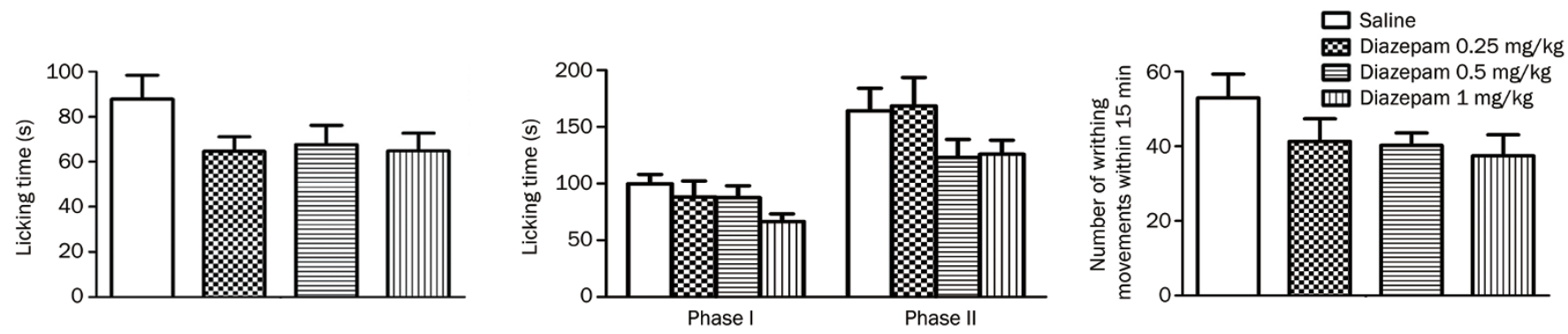

Figure 5. Diazepam did not produce analgesia in thermal- and chemical-stimulated acute pain. (A) mouse tail-flick test, (B) mouse hot-plate test. The basal responses of mice to thermal stimuli were tested before drug administration. (C) mouse capsaicin test, (D) mouse formalin test, (E) mouse acetic acid-induced writhing test. $n=10 /$ group. No statistical significant difference was obtained. 
epam $(0.25,0.5$, or $1 \mathrm{mg} / \mathrm{kg}$, ip) did not significantly reduce paw licking time in the capsaicin test $\left(F_{3,36}=1.717, P>0.05\right)$ (Figure $5 C$ ) or in the formalin test (first phase: $F_{3,36}=1.799, P>0.05$; second phase: $F_{3,36}=1.639, P>0.05$ ) (Figure $5 \mathrm{D}$ ). In the acetic acid-induced writhing test, compared with vehicle treatment, diazepam $(0.25,0.5$, or $1 \mathrm{mg} / \mathrm{kg}$, ip) also did not significantly decrease the number of writhing movements $\left(F_{3,36}=1.532\right.$, $P>0.05$ ) (Figure 5E). However, morphine $(5 \mathrm{mg} / \mathrm{kg}$, sc), which served as a positive control in our experiment, produced significant analgesia in all five of these models (data not shown). In addition, diazepam at a dose of $1.0 \mathrm{mg} / \mathrm{kg}$ (ip) did not decrease locomotor activities (Figure 2). These results showed that diazepam failed to mimic AZA-produced analgesia in acute pain. Enhancement of $\mathrm{GABA}_{\mathrm{A}}$ receptor-mediated inhibition might not play a role in AZA's efficacy in the relief of chemical-stimulated acute pain.

\section{Discussion}

In this study, we report that AZA attenuated chemicalinduced, but not thermal-induced, acute pain in mice. The attenuation of chemical-stimulated acute pain by AZA may not be due to enhancement of $\mathrm{GABA}_{\mathrm{A}}$ receptor-mediated inhibition via inhibiting CA activity but might be due to a peripheral ion channel-related mechanism.

AZA is a potent inhibitor of $\mathrm{CA}^{[18,19]}$ and exerts antinociceptive effects on inflammatory and neuropathic pain by enhancing the efficacy of $\mathrm{GABA}_{\mathrm{A}}$ receptor-mediated inhibition by reducing the production of $\mathrm{HCO}_{3}{ }^{-[7,8]}$. We were interested in investigating whether AZA can also attenuate chemicalinduced acute pain by enhancing $\mathrm{GABA}_{\mathrm{A}}$ receptor-mediated inhibition via inhibiting $C A$. However, our result showed that MZA, another CA inhibitor, did not attenuate thermal- or chemical-induced acute pain in our study. In contrast to AZA either inhibiting CA or affecting other ion channels, MZA merely inhibits CA and has no action on other ion channels. These results indicated that AZA's attenuation of chemicalstimulated acute pain might not be due to enhancement of $\mathrm{GABA}_{\mathrm{A}}$ receptor-mediated inhibition via inhibiting CA. Similar to MZA, diazepam, a positive allosteric modulator of the $\mathrm{GABA}_{\mathrm{A}}$ receptor, cannot attenuate thermal- and chemicalstimulated acute pain at a dose of $0.25,0.5$, or $1 \mathrm{mg} / \mathrm{kg}$ without reducing locomotor activities. Given that a reduction in locomotor activities after drug treatment may lead to a falsepositive result in evaluating the analgesic effect, we selected the proper doses of diazepam, AZA and MZA that did not affect locomotor activities. In fact, a previous study reported that diazepam achieved analgesia in inflammatory and neuropathic pain models at a dose not producing sedation ${ }^{[20]}$. Thus, we thought that the lower dose that we utilized might not be the main cause of the lack of an analgesic effect for diazepam. Although diazepam can activate $\mathrm{GABA}_{\mathrm{A}}$ receptors as a positive allosteric modulator, this drug did not mimic AZA's analgesic effects in our study. In addition, Hansen et al observed that diazepam (1-5 mg/kg, ip) attenuated a capsaicin-induced nociceptive response in the secondary phase $(6-30 \mathrm{~min})$ but not in the first phase $(0-5 \mathrm{~min})^{[21]}$, which was consistent with our observation that diazepam did not relieve capsaicininduced licking behavior at 0-5 min. Indeed, capsaicin could induce primary pain and secondary hypersensitivity, and the $\mathrm{GABA}_{\mathrm{A}}$ receptor might mediate the secondary hypersensitivity. In a formalin test, Kaneko et al observed that the $\mathrm{GABA}_{\mathrm{A}}$ receptor agonists isoguvacine and muscimol attenuated formalin-induced pain behaviors in rats ${ }^{[22]}$, but we did not observe that diazepam produced the same analgesia in mice. The contradiction might be due to the differences in animal species (rat $v s$ mouse) and $\mathrm{GABA}_{\mathrm{A}}$ receptor agonists (isoguvacine or muscimol vs diazepam). Therefore, the mechanisms of AZA's attenuation of chemical-stimulated acute pain are different from that of AZA's attenuation of inflammatory and neuropathic pain. Our results indicated that AZA's relief of chemical-stimulated acute pain does not seem to be due to enhancement of $\mathrm{GABA}_{\mathrm{A}}$ receptor-mediated inhibition via inhibiting CA activity.

In addition to acting as a CA inhibitor, AZA is a non-selective inhibitor of aquaporin $4(\mathrm{AQP} 4)^{[23-25]}$. The $\mathrm{IC}_{50}$ of $\mathrm{AZA}^{\prime} \mathrm{s}$ inhibition of human AQP4-M23-mediated water transport is $0.9 \mathrm{~mol} / \mathrm{L}$, and the reported maximum inhibition of AQP4M23 by AZA is $85 \%^{[23]}$. AQP4 is mainly expressed in glial cells, which are activated in chronic pain but not in acute pain. Our unpublished data show that AQP4 deficiency failed to affect the responses of mice to the acute pain induced by thermal (tail-flick and hot-plate tests), chemical (formalin and capsaicin tests) and mechanical (von Frey hair test) stimuli. Taken together, the results indicate that the inhibition of AQP4 by AZA does not mediate the relief of chemical-stimulated acute pain by AZA.

Additionally, AZA has effects on certain ion channels, such as voltage-gated calcium channels and potassium channels. Voltage-gated calcium channels play a key role in neurotransmitter release from peripheral nociceptor terminals to generate pain ${ }^{[10]}$. The $\mathrm{a}_{1 \mathrm{E}}$ subunit of the voltage-dependent calcium channel (R-type channel) was originally identified as a neuronspecific subunit. It was reported that in tail-flick and hot-plate tests, there were no obvious differences between wild-type and $\mathrm{a}_{1 \mathrm{E}}$ knockout mice, whereas in a formalin test, nociceptive behavior was significantly attenuated in the $a_{1 \mathrm{E}}$ knockout mice ${ }^{[26]}$. It has also been reported that AZA can block $a_{1 E}$ calcium channels ${ }^{[7]}$. In the periphery, the opening of calciumactivated potassium channels is antinociceptive in chemicalstimulated acute pain ${ }^{[7]}$, and AZA can activate these calciumactivated potassium channels ${ }^{[26]}$. Thus, AZA's relief of chemical-stimulated acute pain might be due to the drug's action on certain other ion channels. However, whether peripheral or spinal ion channels mediate AZA's analgesia is still unclear. We observed that intrathecal administration of AZA (10 $\mathrm{nmol} /$ mouse) failed to produce a significant analgesic effect in the capsaicin, formalin and acetic acid-induced writhing tests. Therefore, AZA's analgesic effects on chemical-stimulated acute pain might be due to the drug's action on certain peripheral ion channels, rather than on spinal ion channels.

In this study, we did not observe significant analgesia produced by AZA in thermal-stimulated acute pain. The possible 
explanations are that the ion channels and receptors involved in thermal- and chemical-stimulated acute pain are not completely the same. For example, $5-\mathrm{HT}_{1}$ receptors, except for the $5-\mathrm{HT}_{1 \mathrm{~A}}$ subtype, are involved in the spinally mediated antinociception induced by thermal noxious stimuli ${ }^{[27]}$. The presumptions mentioned above might be the reason that AZA failed to produce analgesia in thermal-stimulated acute pain. Further studies are needed to explain the differences between AZA's effects in thermal-stimulated and chemical-stimulated acute pain. Although there was no significant difference in the main effect of the treatment, suggesting that AZA has no analgesic effect on thermal-stimulated acute pain, the $P$ values for time were all less than 0.05 in the tail-flick and hot-plate tests. The same results were found in the tail-flick and hot-plate tests using MZA and diazepam. The possible reason might be that fluctuations occurred in the data at each time point.

In conclusion, AZA exhibits analgesic effects on chemicalstimulated, but not thermal-stimulated, acute pain. The mechanism of AZA's attenuation of chemical-stimulated acute pain differs from that of AZA's relief of inflammatory and neuropathic pain. Herein, we supposed that the mechanism of AZA's relief of chemical-stimulated acute pain is the interaction of AZA with peripheral ion channels instead of enhancement of $\mathrm{GABA}_{\mathrm{A}}$ receptor-mediated inhibition via inhibiting CA activity. All of the above findings provide a new direction for examining the analgesic effects of AZA.

\section{Acknowledgements}

This work was supported by the National Natural Science Foundation of China (Grant № 81171046).

\section{Author contribution}

Jin LI and Ning WU designed the research; Ya-jie SUN, Ying CHEN, and Chong PANG performed the research; Ya-Jie SUN and Ning WU analyzed the data; Ya-jie SUN and Ning WU wrote the manuscript; and Jin LI revised the manuscript.

\section{References}

1 Moore ND. In search of an ideal analgesic for common acute pain. Acute Pain 2009; 11: 129-37.

2 Kaur IP, Smitha R, Aggarwal D, Kapil M. Acetazolamide: future perspective in topical glaucoma therapeutics. Int J Pharm 2002; 248: 1-14.

3 Velázquez $\mathrm{H}$, Wright FS. Control by drugs of renal potassium handling. Annu Rev Pharmacol Toxicol 1986; 26: 293-309.

4 Kassamali R, Sica DA. Acetazolamide a forgotten diuretic agent. Cardiol Rev 2011; 19: 276-8.

5 Aaslid R. Cerebral autoregulation and vasomotor reactivity. Front Neurol Neurosci 2006; 21: 216-28.

6 Leaf DE, Goldfarb DS. Mechanisms of action of acetazolamide in the prophylaxis and treatment of acute mountain sickness. J Appl Physiol 2007; 102: 1313-22.

7 Radhakrishnan R, Sluka KA. Acetazolamide, a carbonic anhydrase inhibitor, reverses inflammation-induced thermal hyperalgesia in rats. J Pharmacol Exp Ther 2005; 313: 921-7.

8 Asiedu M, Ossipov MH, Kaila K, Price TJ. Acetazolamide and midazolam act synergistically to inhibit neuropathic pain. Pain 2010; 148: 302-8.

9 Voscopoulos C, Lema M. When does acute pain become chronic? $\mathrm{Br}$ J Anaesth 2010; 105: i69-i85.

10 Basbaum Al, Bautista DM, Scherrer G, Julius D. Cellular and molecular mechanisms of pain. Cell 2009; 139: 267-84.

11 Heldt SA, Ressler KJ. Amygdala-specific reduction of alpha1-GABA receptors disrupts the anticonvulsant, locomotor, and sedative, but not anxiolytic, effects of benzodiazepines in mice. J Neurosci 2010; 30: 7139-51.

12 Delporte C, Backhouse N, Inostroza V, Aquirre MC, Peredo N, Silva X, et al. Analgesic activity of Ugni molinae (murtilla) in mice models of acute pain. J Ethnopharmacol 2007; 112: 162-5.

13 Jones CK, Peters SC, Shannon HE. Efficacy of duloxetine, a potent and balanced serotonergic and noradrenergic reuptake inhibitor, in inflammatory and acute pain models in rodents. J Pharmacol Exp Ther 2005; 312: 726-32.

14 Santos AR, Calixto JB. Further evidence for the involvement of tachykinin receptor subtypes in formalin and capsaicin models of pain in mice. Neuropeptides 1997; 31: 381-9.

15 Hylden JL, Wilcox GL. Intrathecal morphine in mice: a new technique. Eur J Pharmacol 1980; 67: 313-6.

16 Couto VM, Vilela FC, Dias DF, Dos Santos MH, Soncini R, Nascimento $\mathrm{CG}$, et al. Antinociceptive effect of extract of Emilia sonchifolia in mice. J Ethnopharmacol 2011; 134: 348-53.

17 Chiba S, Nishiyama T, Yoshikawa M, Yamada Y. The antinociceptive effects of midazolam on three different types of nociception in mice. J Pharmacol Sci 2009; 109: 71-7.

18 Temperini C, Cecchi A, Scozzafava A, Supuran CT. Carbonic anhydrase inhibitors. Comparison of chlorthalidone, indapamide, trichloromethiazide, and furosemide X-ray crystal structures in adducts with isozyme II, when several water molecules make the difference. Bioorg Med Chem 2009; 17: 1214-21.

19 Yang MT, Chien WL, Lu DH, Liou HC, Fu WM. Acetazolamide impairs fear memory consolidation in rodents. Neuropharmacology 2013; 67: 412-8.

20 Knabl J, Witschi R, Hösl K, Reinold H, Zeilhofer UB, Ahmadi S, et al. Reversal of pathological pain through specific spinal GABA receptor subtypes. Nature 2008; 451: 330-4.

21 Hansen RR, Erichsen HK, Brown DT, Mirza NR, Munro G. Positive allosteric modulation of GABA-A receptors reduces capsaicin-induced primary and secondary hypersensitivity in rats. Neuropharmacology. 2012; 63: 1360-7.

22 Kaneko M, Hammond DL. Role of spinal gamma-aminobutyric acidA receptors in formalin-induced nociception in the rat. J Pharmacol Exp Ther 1997; 282: 928-38.

23 Huber VJ, Tsujita M, Yamazaki M, Sakimura K, Nakada T. Identification of arylsulfonamides as aquaporin 4 inhibitors. Bioorg Med Chem Lett 2007; 17: 1270-3.

24 Kim JE, Yeo SI, Ryu HJ, Kim MJ, Kim DS, Jo SM, et al. Astroglial loss and edema formation in the rat piriform cortex and hippocampus following pilocarpine-induced status epilepticus. J Comp Neurol 2010; 518: 4612-28.

25 Tanimura Y, Hiroaki Y, Fujiyoshi Y. Acetazolamide reversibly inhibits water conduction by aquaporin-4. J Struct Biol 2009; 166: 16-21.

26 Pickkers P, Hughes AD, Russel FG, Thien T, Smits P. In vivo evidence for $\mathrm{K}(\mathrm{Ca})$ channel opening properties of acetazolamide in the human vasculature. Br J Pharmacol 2001; 132: 443-50.

27 Nadeson R, Goodchild CS. Antinociceptive role of $5-\mathrm{HT}_{1 \mathrm{~A}}$ receptors in rat spinal cord. Br J Anaesth 2002; 88: 679-84. 